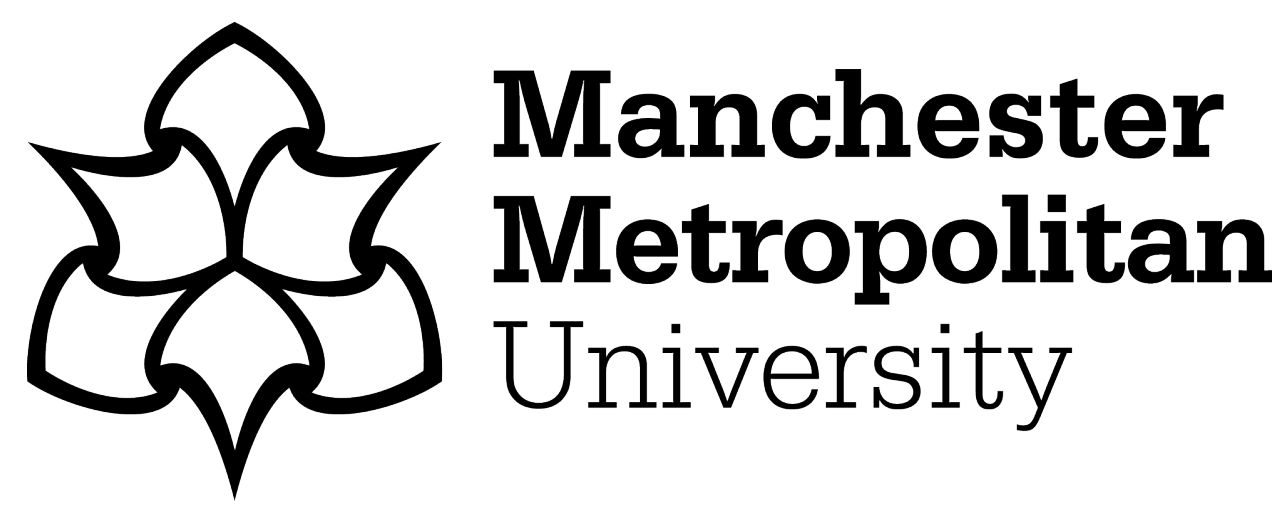

Hagan, Robert ORCID logoORCID: https://orcid.org/0000-0003-1184-229X (2021) Loneliness, older people and a proposed social work response. Journal of Social Work, 21 (5). pp. 1084-1104. ISSN 1468-0173

Downloaded from: https://e-space.mmu.ac.uk/625909/

Version: Accepted Version

Publisher: SAGE Publications

DOI: https://doi.org/10.1177/1468017320927630

Please cite the published version 


\section{Loneliness, older people and a proposed social work response}

\section{Robert Hagan}

Senior lecturer in social work, Manchester Metropolitan University, Room 2.22, Brooks Building, MANCHESTER, M15 6GX

Email: r.hagan@mmu.ac.uk

There are no conflicts of interest to report. 
In the United Kingdom (UK), loneliness has become a public health issue (HM Government, 2018), following profile building work by the Campaign to End Loneliness, established in 2011, and the Jo Cox Commission on Loneliness, set up in 2016. Whilst both organisations indicate that loneliness can affect anyone at any time (Jo Cox Loneliness, 2017; Joping \& Barnett, 2014), often loneliness initiatives target older populations (Fulton \& Jupp, 2015). This includes promoting community-based approaches (Collins \& Wrigley, 2014) and appointing a minister for loneliness (HM Government, 2018).

Given increasing attention on loneliness, social workers, especially those working with older people, require more knowledge on the nuances of the concept. This article aims to summarise thinking around loneliness, explain key research messages, and identify how some ideas have been misrepresented or exaggerated. After discussing misconceptions, the article will then propose a model for active social work practice.

\section{Introducing loneliness}

Loneliness is multi-faceted, with a discrete definition difficult to determine. As loneliness is subjective, it is distinct from social isolation, which is the objective absence or lack of social relationships or support (Coyle \& Duggan, 2012). Nor is it being alone, as this would exclude those who feel lonely amidst a substantive social circle (Griffin, 2010). Loneliness is unpleasant and unchosen, demarcated by feelings of helplessness, disconnection, confinement and fears of dependency (Kitzmuller et al., 2018). An evolutionary conceptualisation of loneliness describes it as a trigger to seek out social bonds for security (Cacioppo \& Patrick, 2008; O'Luanaigh \& Lawlor, 2008). Loneliness is not only important in terms of belonging but also in feeling secure.

The subjective nature of loneliness is such that "individuals with a low propensity for loneliness may thrive in socially isolated conditions, while those with a high propensity for loneliness [and integrated into a visible social network] may require more social connectedness" (McHugh et al., 2016: 2). 
Loneliness occurs in the absence of meaningful relationships or from dissatisfaction with existing ones (Heinrich \& Gullone, 2006). It is the discrepancy between one's emotional and/or social needs and wants, and the reality of social experience (Killeen, 1998).

Experiences of loneliness are not the same throughout the life course. For adolescents and younger adult populations, loneliness relates to dissatisfaction with or marginalisation from social relationships with peers and potential romantic partners (Woodhouse et al., 2012). Being alone does not commonly correlate with loneliness for younger people, except at specific times such as weekend evenings, when there is a 'normal' expectation to be socialising with peers (Larson, 1999). However, older people's loneliness is more likely to be "consequent to an occurrence" (Wood, 1986: 203), where an uncomfortable transition, such as bereavement, a health decline or impairment, or decreased independence, results in a substantial loss in contact with meaningful others.

Whilst loneliness is subjective, conceiving this merely in relation to individuals' internal feelings negates ecological systems affecting older adults and their communities. Older people who are poorer or living in socially deprived neighbourhoods, who have poorer levels of education, lower household income, or lack access to a car or social activities are at greater risk of loneliness (Greer et al., 2016).

\section{Methodology}

Examining research literature over time established a knowledge base on studies investigating loneliness in later life. Initially, a scoping review of seven electronic databases (Scopus, ASSIA, CINAHL Plus, Medline, Psycinfo, Social Services Abstracts and Sociological Abstracts) searched for studies relating to loneliness and older people from 2000 to 2012 . Search terms used included old*, eld* or

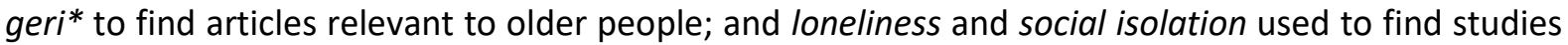
on loneliness. Whilst social isolation is a poor synonym for loneliness, this was included as this term is sometimes used interchangeably when describing loneliness. This search initially explored 
interventions effective in addressing loneliness, with results published elsewhere (Hagan et al., 2014). Following this, a Zetoc Alert, a service providing email alerts matching search criteria for studies on loneliness and older people (Jisc, no date), was set up, ensuring access to research beyond the years initially searched. Furthermore, the author found other studies through hand searching references and grey literature, including reports and surveys from organisations such as Age UK, Campaign to End Loneliness and the Joseph Rowntree Foundation. An inductive approach informed this article as findings emerged over time and through ongoing analysis. Summarising the messages accrued from searching led to the following, which will be explored:

- how literature on loneliness in later life leads to the identification of discrete subcategories of loneliness.

- how certain misconceptions are held in particular influential media and how research challenges these.

- applying this learning to social work practice to develop a hypothetical model for social workers to apply with potentially lonely older people.

\section{Addressing loneliness}

Over the last 15 years or so, academics have evaluated interventions tackling older people's loneliness (Gardiner et al., 2018; Hagan et al., 2014, Dickens et al, 2011; Masi et al, 2011; Heinrich \& Gullone, 2006; Cattan et al, 2005; Findlay, 2003). Whilst reviews report considerable variation, reductions in loneliness were sometimes, though not always, reported in both group and one-to-one approaches. One meta-analysis concluded that work addressing 'maladaptive social cognition' would be most valuable (Masi et al., 2011). Loneliness can be subdivided into discrete experiences, where different approaches may be required (Dahlberg \& McKee, 2014).

\section{Subdivision One: Emotional and social loneliness}


The terms 'emotional loneliness' and 'social loneliness' are commonly associated with Robert Weiss (1973). Weiss conceptualised emotional loneliness as reflecting a keenly felt loss or absence of a specific close relationship or attachment figure (O'Luanaigh \& Lawlor, 2008). This relationship is demarcated by a level of intimacy where the individual feels they have a trusted confidant, often a spouse or partner, but possibly another family member or close friend (Dong et al., 2012). The absence of this intimate companion, with whom one shares personal life events, leads to the world feeling empty (Kitzmuller et al., 2018).

In contrast, social loneliness indicates detachment from a desired social network or friends, who do not meet expectations for contact and support (Dahlberg \& McKee, 2014). For example, migrants may report greater social loneliness, due to poor social networks where they live (Koelet \& de Valk, 2016). Emotional loneliness may be best addressed via introducing a new confidant style relationship, whilst social loneliness could be overcome through strengthening the individual's social network.

\section{Subdivision Two: State (or situational) and trait (or chronic) loneliness}

If older people experience loneliness due to stressful or traumatic life events or transitions, they experience temporary or 'state' loneliness, a mutable condition which should not be problematic and passes with time (Shiovitz-Ezra \& Ayalon, 2012).

In contrast, 'trait' or chronic loneliness occurs over a longer period, emerging from impaired thinking and unhealthy personal habits (Martin-Maria et al., 2020), or the cumulative impact of traumatic events or childhood abuse (Barrett \& Mosca, 2012; Palgi et al., 2012). It is associated with personality traits such as neuroticism and shyness, which lead to social withdrawal, hypervigilance in relation to social interactions, and distrust of relationships (van Wrinkel et al., 2017). Someone experiencing trait loneliness may not so readily recognise themselves as lonely than those with state loneliness, as loneliness has become ingrained (van Roekel et al., 2018). Whilst someone with state loneliness may 
desire social relations, an individual with trait loneliness may be warier. Although factors within state and trait loneliness do not always strongly correlate (Yi et al., 2018), those with high levels of trait loneliness also report high levels of state loneliness (van Roekel et al., 2018). Therefore, whilst the types of loneliness are discrete, they may converge. Nevertheless, these two populations may require differing interventions with psychological input more appropriate for chronic loneliness.

The above highlights that loneliness experiences vary. Given the type of loneliness presenting, what might work for one may be unsuccessful for another. An unsophisticated approach to loneliness could result in inappropriate action. The following section outlines four misconceptions that could arise following a cursory assessment of needs.

\section{Misconceptions}

The four following misconceptions are not myths: each has elements of truth. They are visible in media messages from respected sources, or have emerged or been examined and challenged in research. They could become generalisations that, without analysis, stereotype the older person with whom a social worker is engaging, resulting in an unneeded or inappropriate intervention.

\section{Misconception One: Older people are particularly lonely}

In the UK, the NHS reports that older people are "especially vulnerable to loneliness" (NHS, 2018). A previous study on loneliness myths questioned whether loneliness was specifically a problem for older people and concluded there was partial support (Dykstra, 2009). However, surveys reporting fears of loneliness in later life highlight this is more a concern for younger adults and these anxieties reduce as one ages, indicating that fears around loneliness are exaggerated. In one survey, $46 \%$ of those between 15 and 23 associated later life with loneliness compared with 25\% of those aged 65 and over (Independent Age/Mori, 2005, see Figure 1). In another, $61 \%$ of $18-34$ year olds, $47 \%$ of $35-64$ year 
olds and $33 \%$ of those $65+$ identified loneliness as a serious problem for older people (Abramson \& Silverstein, 2006).

\section{[Insert Figure 1 around here]}

The wider literature consistently reports that those who feel always or often lonely in later life are in the minority, roughly equating to between eight and 12\% (see Table 1; also Scharf, 2015; Davidson \& Russell, 2015), though this figure may extend to approximately $40 \%$ when including those who report sometimes feeling lonely. In contrast, adolescents and younger adults often report higher levels of loneliness than other age groups (Luhmann \& Hawkley, 2016; Qualter et al., 2015; Victor \& Yang, 2012). Nevertheless, one should not underestimate the pain of loneliness in later life and there are higher levels of reported loneliness as one enters very old age (Brittain et al., 2017; Dykstra, 2009).

\section{[Insert Table 1 around here]}

\section{Misconception Two: Older people who live alone are lonely}

Summarising loneliness, the NHS explicitly equates loneliness with living alone, indicating, without further comment or explanation, that over two million of those aged 75 and over live alone (NHS, 2018; also Age UK, 2019). Additionally, whilst the Campaign to End Loneliness' Facts on Loneliness note various factors contributing to older people's loneliness, two bullet points refer to living alone without explaining what this means (Campaign to End Loneliness, no date). Kharicha et al. (2007) report that media coverage has conflated and sensationalised living alone and loneliness. Older people who live on their own do often report greater loneliness (Chen et al., 2014; Nyqvist et al., 2013), however, Victor et al. (2009) note that the majority of those in later life living alone are not lonely. These authors suggest that what may be more salient are the factors leading to living alone. Variations in health and well-being, which may restrict freedom of movement or access to close social 
relationships, are more likely than living arrangements to lead to loneliness (Smith \& Victor, 2019; Hawkley \& Kocherginsky, 2018).

Paths to older people living alone include widowhood, separation or divorce, though others have been ever single or spent most of their adult life living on their own, and therefore are less likely to experience this loneliness precipitating transition. Data from the English Longitudinal Study on Ageing indicate that ever single people are more likely to be hardly ever lonely than those separated/divorced or widowed (see Table 2).

\section{[Insert Table 2 around here]}

Nevertheless, living alone can have negative consequences, especially as one becomes very old and when mobility is increasingly restricted. For example, one quarter of those aged $75+$ and living alone do not see or speak with someone every day (Jopling, 2015). Multi-morbidities often correlate with increasing age (Savva et al., 2011) and poor health or decreasing mobility restrict older people's independence and ability to leave the house (Warner \& Adams, 2016; Burholt \& Scharf, 2014). Whilst solitude can be valuable (Lee, 2013), studies of solitary confinement describe profound negative effects on mental health for those living in an entrapped, solitary states (Metzner \& Fellner, 2010), something unchosen by older persons with mobility difficulties.

Considering this, social workers may wish to move an older person away from a solitary living arrangement due to perceived loneliness, although long-time residence in one's own home in a familiar location may actually guard against loneliness (van den Berg et al., 2016). Moving to a new location could isolate (Saito et al., 2012) and those living in nursing or care homes are more likely to report loneliness (Brittain et al., 2017; Davidson \& Russell, 2015). Living with adult children is usually undesirable and may not alleviate loneliness (Kitzmuller et al., 2018; Nyqvist et al, 2013), with resulting 
increases in higher levels of emotional loneliness (Hagan et al., 2017) and exclusion from social relationships (Kneale, 2012). This kind of move has been described as "a last resort" (Fengler et al, 1983: 359).

Additionally, whilst marriage often buffers against loneliness (Warner \& Kelley-Moore, 2012; ShiovitzEzra \& Leitsch, 2010), loneliness emerges in strained or unhappy marital relationships (Stokes, 2016; Warner \& Adams, 2016). Stokes notes that if one spouse reports loneliness, the other probably will too.

\section{Misconception Three: Families meet older people's social needs}

Concerns around the fragmentation of family networks has informed reporting on loneliness in recent years (WRVS, 2012). European research has also investigated how countries that emphasise closer family bonds often report higher levels of loneliness (Fokkema et al., 2012). Close family relationships increase in importance in later life, particularly after losing a spouse (Pahl \& Prevalin, 2005) and older people prefer immediate kin for providing instrumental personal care, financial support and guidance with critical decisions (Victor et al, 2009). However, whilst spousal loss can lead to profound emotional loneliness, other family members are less likely to compensate for feelings of loneliness than friends and a wider social network (Steed et al., 2007).

Whilst kin relationships may be bound by obligation (Fiori et al., 2008), non-kin friendships are voluntary, more informal and less burdensome (Wenger, 1997). Friendships give stronger protection against subjective loneliness compared with having only access to kin and especially adult children (Nyqvist et al, 2013). A family-centric network reflects greater care needs and reduced independence (Keating et al., 2003), which impinges upon contact with non-kin and leads to greater lonelinesss (Kirekevold et al., 2013). A strained relationship with family is one of the strongest predictors of loneliness, particularly for those not married (Shiovitz-Ezra \& Leitsch, 2010). 
Older people value being able to socialise and maintaining friendships is a core goal when ageing (Katz et al, 2011). However, one UK survey found that $12 \%$ of those aged 65 and over have no contact with friends (Davidson \& Russell, 2015). Similar aged peers are particularly valued as they often share the same worldview (Routasalo et al., 2006). However, as older people age, the chances of losing peer group friends increases, leading to accumulating feelings of loss in later life, sometimes called the “pain of survivorship" (Hagestad \& Uhlenberg, 2006: 645).

\section{Misconception Four: Loneliness is tackled only by addressing loneliness directly}

Masi et al's (2011) recommendation that interventions tackle individuals' own maladaptive reasoning to overcome loneliness could be valuable when facing chronic loneliness. Whilst evaluations for psychological approaches are often more robust than other methods, outcomes are variable and may be explained by other factors unrelated to therapy (Gardiner et al., 2018). It may infer sole responsibility upon the individual to recover from their loneliness experience, neglecting the impact of unwelcome transitions experienced, which more commonly correlate with loneliness in older people. As a result, thought must consider the ecological systems within which the older person is located and potential deficits therein.

Perhaps more pertinently, tackling loneliness head on is simply unappealing. Admitting to loneliness means admitting to shame, failure and passivity (Shiovitz-Ezra \& Ayalon, 2012), as demonstrated by one study's findings that one third of respondents would feel embarrassed to admit they are lonely (Griffin, 2010). Another states that $80 \%$ of over 85 s have not told their children they are lonely (Kempton \& Tomlin, 2014). Talking about loneliness makes participants feel uncomfortable and guilty (Heenan, 2011). As one research respondent articulates: 
"I think I know why I feel alone and isolated. I think I know, I don't need someone to tell me." (Kharachi et al., 2017: 7)

Group or individual activities based around loneliness, therefore, are unlikely to be successful. Experts surveyed by Jopling (2015: 12) suggest that approaches that were "framed not as loneliness solutions, but as holistic and person-centred services, aimed at promoting healthy and active ageing, building resilience and supporting independence" were more likely to be effective. Social groups do not have to have 'addressing loneliness' as an aim to be effective (Davidson \& Russell, 2015). Instead, tackling loneliness by 'stealth' by linking older people to existing interests may be more attractive to potential participants.

\section{Discussion: How might social workers address older people's loneliness?}

The rising profile of loneliness, particularly for older people, precipitates a desire in social workers to respond to service users at risk. The above narrative cautions against assuming individuals are lonely because they live alone or are increasing in age, or that increased contact with family may be the most appropriate response, or even that addressing loneliness directly is always advisable. This section now considers how social workers could respond.

This article has indicated that loneliness cannot be easily conceptualised in one way (Jopling, 2015). Differentiating the type of loneliness experienced is vital (Shiovitz-Ezra \& Ayalon, 2012) and particular interventions are effective with certain individuals at certain times, but not with others (Davidson \& Russell, 2015). For example, cognitive approaches, recommended by Masi et al. (2011) are more suitable for those who experience chronic or 'trait' loneliness. For many older people, it is more likely later life transitions precipitate loneliness, and these transitions relate to profound losses, especially in terms of a confidant, or impairments leading to compromised access to a desired social network. In this way, addressing the ecological systems surrounding the older person becomes more 
meaningful. Importantly, strong links with family at the expense of friends, peers and other non-kin relationships could indicate a greater vulnerability to loneliness (De Jong Gierveld et al., 2012). In these situations, social workers should prioritise how they can bolster valued existing networks, which may be more beneficial than introducing new ones (Jopling, 2015; Harries \& de Las Casas, 2013; Walker et al., 2013; Ngan, 2011). Some may not wish to embark upon new relationships due to health decline (Smith, 2012). In line with theory on socio-emotional selectivity (Cartensen et al., 1999) and compensation (Baltes, 1997), older people's well-being is not so much associated with any type of social engagement but only that which they choose freely and find meaningful (Rozanova et al., 2012). Scoping an individual's social network and offering assistance with accessing existing relationships could be valued. Promoting being part of a 'locally integrated support network' (Wenger, 1997), one which combines friends, family and neighbours, and where the individual feels comfortable in their neighbourhood and connected to organisations therein, has been posited as a successful, low key way of addressing loneliness (Gray, 2009).

Social workers may be anxious that promoted initiatives are unsuitable for the presenting type of loneliness. If, for example, emotional loneliness is best remedied by the (re)introduction of a confidant-style relationship, would integrating individuals into social groups be appropriate - as surely social work does not have a quasi-dating consultant role? Although social and emotional loneliness have been demonstrated to be conceptually different (Dahlberg \& McKee, 2014), nevertheless researchers have found certain social interventions to be effective in reducing emotional loneliness. These include support groups aimed at recently widowed older people (Chow et al., 2018; Stewart et al., 2001), groups promoting community connections (Coll-Planas et al., 2017), day centre reablement group programming (Hagan et al., 2017) and internet usage (Fokkema \& Knipscheer, 2007). Interventions involving these kinds of social interaction and support may not produce confidant style relationships, nevertheless improvements reflect compensatory benefits (Baltes, 1997). Therefore there remains validity in social workers adopting these approaches. 
Active engagement in later life remains a crucial goal for many older people (Gray et al., 2014), yet many of those lonely have failing mobility or health (Lilja et al., 2017). For those whose network shrinks due to physical health declines, mobility difficulties and decreased car usage, local neighbourhoods become an increasingly important social space, where informal interactions take on an amplified meaning (Gardner, 2011). Whilst some move to retirement villages or sheltered housing schemes, it is not unusual for loneliness to accompany the loss of familiar, old neighbourhoods (Adams et al., 2004). Rather, many older people may not wish to move from communities in which they have been embedded all their lives and where they have strong connections (Walsh et al., 2012). However, they may also experience dissonance in the context of communities and neighbourhoods that are constantly changing (Goll et al., 2015; Walker et al., 2013; Rozanova et al., 2012). Where once familiar resources, such as libraries, community groups, local shops and post offices, are at risk of closure and with families moving away, feelings of isolation increase, leading to perceptions that the changing social environment has become hostile or alienating (Galenkamp \& Deeg, 2016; Mortimer, 2016; Walsh et al., 2012). This may lead to desired lifestyles choices becoming inaccessible without access to a car (Curl et al., 2013) and, even for those older people who drive, there may be greater reluctance to drive at night or in bad weather (Adler \& Rottunda, 2006). Social workers should consider surveying services and facilities within walking distance (Ni Lieme \& Connolly, 2015), though also bear in mind that some older people may still find these hard to reach due to poorly maintained pavements and pathways (Walker et al., 2013). There may then be further need for advocating at higher levels on behalf of individuals and communities regarding neighbourhood resourcing.

Including the 'oldest old' or those particularly frail, as well as those without adequate financial resources to easily access social or cultural activities (Ni Lieme \& Connolly, 2015), is crucial. Having a lower income is a barrier to participation, as are anxieties about health, falls and medication management (Goll et al., 2015) and those with a lower socioeconomic status are less likely to have a 
supportive social network (Martire \& Franks, 2014). Whilst social workers will be keen to promote individuals' own freedom regarding accessing appropriate social activities, some remain inaccessible due to cost (Liljas et al., 2017; Rozanova et al., 2012).

To summarise these key ideas, a hypothetical model is proposed (see Figure 2), recommending a person-centred approach be adopted, promoting primarily the maintenance of existing networks but not ruling out, especially for those experiencing difficulties with health, mobility and independent movement, introducing group or befriending initiatives. Additionally, taking on board previous considerations about maladaptive social cognition, an additional pathway that particularly relates to chronic loneliness could be activated for those whose loneliness has persisted over the life course.

\section{[Insert Figure 2 here]}

\section{Should social workers initiate specific programmes to address loneliness?}

In one study, one respondent notes that some initiatives introduced to promote older people's social activities feel patronising: "We have had things in the past that were useless. Somebody talking at you like you were a child" (Heenan, 2011: 482). Unsurprisingly, as at other stages in the life course, older people have little tolerance of social activities peripheral to their needs (Goll et al., 2015; Walker et al., 2013). If social workers are considering interventions, group based approaches should be purposeful, not just advertised as 'social contact', especially so for men (Goll et al., 2015; Davidson \& Russell, 2015; Devine et al., 2014). The promotion of specific shared and intergenerational interests has merit (Kharachi et al., 2017; Jopling, 2015), particularly where older people feel excluded from intergenerational relationships that are not family based (Lloyd, 2008). If befriending schemes are promoted, serious consideration needs to be given to how individuals are matched and introduced. Whilst befriending can reduce loneliness (Lawlor et al., 2014), especially for the 'oldest old' (Moriarty \& Manthorpe, 2017), it has been criticised as doing little to change the disadvantaged situation of the 
service recipient (Devine et al., 2014) and participants have reported uncertainty over volunteers' motivations (Kharachi et al., 2017). For frailer individuals, the home becomes increasingly the hub for health and social care (Thompson, 2016) and, at this point, engagement with home visiting professionals and volunteers take on added meaning. However, one should not presume that interventions need increased social contact with others: literature reviews have reported success from projects ranging from the introduction of pets (and robot pets) and online technologies (Gardiner et al., 2018; Hagan et al., 2014).

In line with a person-centred approach, Age UK recommend individualised assessment via a guided conversation with older people, exploring what they consider solutions to their social situations (Mortimer, 2016; Jopling, 2015). A gentle persistence with respectful trust building and preferably face-to-face contact is vital for social workers wishing to promote meaningful social engagement (Liljas et al., 2017; Walker et al., 2013). This may lead to more distinctive, individualised programmes of care that fit with the current personalisation agenda, but with associated concerns that desired services may be either unavailable, inaccessible or unaffordable, and also the difficulties some older people may face managing these complex processes (Ray et al., 2014). Budget restraints may not allow every service to be feasibly provided and so what is prioritised, and who takes responsibility, can be prickly questions in times of austerity (Ni Lieme \& Connolly, 2015).

Finally, older people's experience of loneliness should not be seen as inevitable or irrevocable (Warburton et al, 2016). Studies on bereavement highlight that initial poor impacts on well-being, including loneliness, reduce over time (Stone et al, 2013). In fact, bereavement and loss of social network act as cruel prompts to participate in new social activities (Ni Lieme \& Connolly, 2015). Social work engagement does not need to be unduly intrusive or last longer than required: older adults may resolve their own issues with loneliness and social disconnection, in contrast to cultural portrayals of their being helpless and vulnerable victims, lacking the capacity to manage their own lives (Bozarro et 
al., 2018; Coudin \& Alexopoulos, 2010). Additionally, social workers should consider activities that allow older people opportunities to reciprocate, rather than receive a service passively. Community approaches where older adults have been involved in the design of interventions have had success in reducing loneliness (Gardiner et al., 2018). When individuals merely receive support, this can lead to feelings of unhappiness, guilt, resentment and obligation (Dalley et al., 2012). Opportunities to give support promote autonomy, value and well-being in later life, lift morale and increase meaningful social integration (Kitzmuller et al., 2018; McLeod et al., 2008). If this remains at the forefront of social workers' considerations, fruitful and valuable ways to promote older people's own desired social engagement that reduces their own subjective loneliness may result.

\section{Limitations}

The above messages are developed from a scoping review and therefore are not exhaustive. A more comprehensive systematic approach could uncover different findings.

\section{Concluding Message}

Whilst the numbers of older people experiencing loneliness are in a minority, this experience can nevertheless feel devastating. This survey has highlighted that older people prize their existing social networks though, if individuals only have connections with kin, then loneliness is more likely to be higher. Social workers should promote individuals' attachment to existing groups or, if appropriate, introduce them to groups that may have a wider age range but which focus on topics of interest, rather than discuss loneliness. The promotion of targeted interventions, which take account of individual need and ability, much like those piloted by Age UK, are person-centred and appealing. These approaches are less likely to specifically address loneliness in a conceptual sense, as this is unattractive to most individuals. However, they may be quite time intensive and are somewhat reliant on either responsive existing social networks or accessible community resources. Social workers should also be 
willing to advocate for individuals whose mobility or independence is compromised and address inadequate community or neighbourhood needs at a wider policy level.

\section{Statement on ethics and funding}

This study was based on a review of relevant literature and no direct work was conducted with individuals or organisations. Therefore no ethical approval nor funding was required. 


\section{Bibliography}

Abramson, A. \& Silverstein, M. (2006). Images of aging in America 2004. AARP/ University of Southern California.

Adams, K. B., Sanders, S. \& Auth, E. A. (2004). Loneliness and depression in independent living retirement communities: Risk and resilience factors. Aging \& Mental Health, 8, 475-485. https://doi.org/10.1080/13607860410001725054

Adler, G. \& Rottunda, S. (2006). Older adults' perspectives on driving cessation. Journal of Aging Studies, 20, 227-235. https://doi.org/10.1016/j.jaging.2005.09.003

Age UK (2019). Loneliness. https://www.ageuk.org.uk/information-advice/healthwellbeing/loneliness/

Baltes, P. B. (1997). On the incomplete architecture of human ontogeny: Selection, optimization and compensation as foundation of developmental theory. American Psychologist, 52, 366-380. https://doi.org/10.1037/0003-066X.52.4.366

Barrett, A. \& Mosca, I. (2012). Social isolation, loneliness and return migration: Evidence from older Irish adults. Journal of Ethnic and Migration Studies, 39, 1659-1677. https://doi.org/10.1080/1369183X.2013.833694

Brittain, K., Kingston, A., Davies, K., Collerton, J., Robinson, L. A., Kirkwood, T. B., Bond, J. \& Jagger, C. (2017). An investigation into the patterns of loneliness and loss in the oldest old-Newcastle 85+ Study. Ageing \& Society, 37, 39-62. https://doi.org/10.1017/S0144686X15001142

Burholt, V. \& Scharf, T. (2014). Poor health and loneliness in later life: The role of depressive symptoms, social resources and rural environments. Journals of Gerontology Series B: Psychological Sciences \& Social Sciences, 69, 311-324.

https://doi.org/10.1093/geronb/gbt121 
Cacioppo, J. T. \& Patrick, W. (2008). Loneliness: Human nature and the need for social connection. WW Norton.

Campaign to end loneliness. (n.d.). The facts on loneliness.

https://www.campaigntoendloneliness.org/the-facts-on-loneliness/

Cartensen, L. L., Isaacowitz, D. M. \& Charles, S. T. (1999). Taking time seriously: A theory of socioemotional selectivity. American Psychologist, 54, 165-181.

https://doi.org/10.1037/0003-066X.54.3.165

Cattan, M., White, M., Bond, J. \& Learmouth, A. (2005). Preventing social isolation and loneliness among older people: A systematic review of health promotion interventions. Ageing \& Society, 25, 41-67. https://doi.org/10.1017/S0144686X04002594

Chen, Y., Hicks, A., \& While, A. E. (2014). Loneliness and social support of older people in China: A systematic literature review. Health \& Social Care in the Community, 22, 113-

123. https://doi.org/10.1111/hsc.12051

Chow, A. Y., Caserta, M., Lund, D., Suen, M. H., Xiu, D., Chan, I. K., \& Chu, K. S. (2018). Dual-process bereavement group intervention (DPBGI) for widowed older adults. The Gerontologist, 59, 983-994. https://doi.org/10.1093/geront/gny095

Collins, A. B. \& Wrigley, J. (2014). Can a neighbourhood approach to loneliness contribute to people's well-being? Joseph Rowntree Foundation. https://www.basw.co.uk/system/files/resources/basw_40417-8_0.pdf

Coll-Planas, L., del Valle Gomez, G., Bonilla, P., Masat, T., Puig, T., \& Monteserin, R. (2017). Promoting social capital to alleviate loneliness and improve health among older people in 
Spain. Health \& Social Care in the Community, 25, 145-

157. https://doi.org/10.1111/hsc.12284

Coudin, G., \& Alexopoulos, T. (2010). 'Help me! I’m old!' How negative aging stereotypes create dependency among older adults. Aging \& Mental Health, 14, 516-523. https://doi.org/10.1080/13607861003713182

Coyle, C. E. \& Duggan, E. (2012). Social isolation, loneliness and health among older adults. Journal of Aging and Health, 24, 1346-1363. https://doi.org/10.1177/0898264312460275

Curl, A. L., Stowe, J. D., Cooney, T. M. \& Proulx, C. M. (2013). Giving up the keys: How driving cessation affects engagement in later life. The Gerontologist, 54, 423-433. https://doi.org/10.1093/geront/gnt037

Dahlberg, L. \& McKee, K. J. (2014). Correlates of social and emotional loneliness in older people: Evidence from an English community study. Aging \& Mental Health, 18, 504-514. https://doi.org/10.1080/13607863.2013.856863

Dalley, G., Gilhooly, K., Gilhooly, M., Barnett, J., Gobet, F., Harries, P., Niblock, S, Sullivan, M. P. \& Victor, C. R. (2012). Risk, trust and relationships in an ageing society. Joseph Rowntree Foundation/Brunel University. https://www.jrf.org.uk/report/risk-trust-and-relationshipsageing-society

Davidson, S. \& Russell, P. (2015). Loneliness evidence review. Age UK. https://www.ageuk.org.uk/globalassets/age-uk/documents/reports-and-publications/reportsand-briefings/health--wellbeing/rb_june15_lonelines_in_later_life_evidence_review.pdf

De Jong Gierveld, J. J., Dykstra, P. \& Schenk, N. N. (2012). Living arrangements, intergenerational support types and older adult loneliness in Eastern and Western Europe. Demographic Research, 27, 167-200. https://www.jstor.org/stable/26349921 
Devine, P., Carter Anand, J., Montgomery, L., Ni Dhonaill, C. \& O’Hagan, L. (2014). A review of service provision for men aged 50+ (Belfast). Belfast: Public Health Agency/Queen's University/ Volunteer Now. https://pure.qub.ac.uk/en/publications/a-review-of-service-provision-formen-aged-50-belfast

Dickens, A. P., Richards, S. H., Greaves, C. J. \& Campbell, J. L. (2011). Interventions targeting social isolation in older people: a systematic review. BMC Public Health, 11. doi: 10.1186/1471-245811-647.

Dong, X., Chang, E. S., Wong, E. \& Simon, M. (2012). Perception and negative effect of loneliness in a Chicago Chinese population of older adults. Archives of Geronotology \& Geriatrics, 54, 151159. https://doi.org/10.1016/j.archger.2011.04.022

Dykstra, P.A. (2009). Older adult loneliness: Myths and realities. European Journal of Ageing, 6, 91100. https://link.springer.com/article/10.1007/s10433-009-0110-3

Fengler, A. P., Danigelis, N. \& Little, V. C. (1983). Later life satisfaction and household structure: Living with others and living alone. Ageing \& Society, 3, 357-377. https://doi.org/10.1017/S0144686X00010230

Finlay, R. A. (2003). Interventions to reduce social isolation amongst older people: Where is the evidence? Ageing \& Society, 23, 647-658. https://doi.org/10.1017/S0144686X03001296

Fiori, K. L., Consedine, N. S. \& Magai, C. (2008). Ethnic differences in patterns of social exchange among older adults: The role of resource context. Ageing \& Society, $28,495-$ 524. https://doi.org/10.1017/S0144686X07006940

Fokkema, T., De Jong Gierveld, J., \& Dykstra, P. A. (2012). Cross-national differences in older adult Ioneliness. The Journal of Psychology, 146, 201-228. https://doi.org/10.1080/00223980.2011.631612 
Fokkema, T. \& Knipscheer, K. (2007). Escape loneliness by going digital: A quantitative and qualitative evaluation of a Dutch experiment in using ECT to overcome loneliness among older adults. Aging and Mental Health, 11, 496-504. https://doi.org/10.1080/13607860701366129

Fulton, L. \& Jupp, B. (2015). Investing to tackle loneliness: A discussion paper. Cabinet Office/Calouste Gulbenkian foundation. https://gulbenkian.pt/ukbranch/publication/investing-to-tackle-loneliness-a-discussion-paper/

Galenkamp, H. \& Deeg, D. J. H. (2016). Increasing social participation of older people: Are there different barriers for those in poor health? European Journal of Ageing, 13, 87-90. doi: 10.1007/s10433-016-0379-y

Gardiner, C., Geldenhuys, G. \& Gott, M. (2018). Interventions to reduce social isolation and Ioneliness among older people: an integrative review. Health \& Social Care in the Community, 26, 147-157. https://doi.org/10.1111/hsc.12367

Gardner, P. J. (2011). Natural neighbourhood networks: Important social networks in the lives of older adults aging in place. Journal of Aging Studies, 25, 263-271. https://doi.org/10.1016/j.jaging.2011.03.007

Goll, J. C., Charleworth, G., Scior, K. \& Stott, J. (2015). Barrier to social participation among lonely older adults: The influence of social fears and identity. PLoS ONE 10: 2. doi:10.1371/ journal.pone.0116664

Gray, A. (2009). The social capital of older people. Ageing \& Society, 29, 531. https://doi.org/10.1017/S0144686X08007617 
Gray, A. M., Devine, P., Titterington, V., Johnston, L. \& Henkin, N. (2014). Collaborating towards an Age-friendly Northern Ireland. Ark Ageing/Queen's University/Ulster University. https://www.ark.ac.uk/ap/wp-content/uploads/2014/11/collbrief.pdf

Greer, E., Ferguson, S. \& Ellis, G. (2016). Mapping isolation and loneliness amongst older people in Belfast. Age-friendly Belfast/Queen's University. https://pureadmin.qub.ac.uk/ws/portalfiles/portal/148232006/Mapping_Loneliness_Belfast.p df

Griffin, J. (2010). The lonely society? Mental Health Foundation. https://www.mentalhealth.org.uk/sites/default/files/the_lonely_society_report.pdf

Hagan, R. J., Manktelow, R., Taylor, B. J. \& Mallett, J. (2014). Reducing loneliness amongst older people: A systematic search and narrative review. Aging \& Mental Health, 18, 683-693. https://doi.org/10.1080/13607863.2013.875122

Hagan, R. J., Taylor, B. J., Mallett, J., Manktelow, R., \& Pascal, J. (2017). Older people, loss and Ioneliness: The troublesome nature of increased contact with adult children. Illness, Crisis \& Loss. doi: 1054137317742235.

Hagestad, G. O. \& Unlenberg, P. (2006). Should we be concerned about age segregation? Some theoretical and empirical explorations. Research on Aging, 28, 638-653. https://doi.org/10.1177/0164027506291872

Harries, E. \& de Las Casas, L. (2013). Who will love me, when I'm 64? New Philanthropy Capital/Relate. https://www.relate.org.uk/sites/default/files/publication-when-im-642013.pdf 
Hawkley, L. C. \& Kocherginsky, M. (2018). Transitions in loneliness among older adults: A 5-year follow-up in the National Social Life, Health, and Aging Project. Research on Aging, 40, 365387. https://doi.org/10.1177/0164027517698965

Heenan, D. (2011). How local interventions can build capacity to address social isolation in dispersed rural communities: A case study from Northern Ireland. Ageing International, 36, 475-491. doi $10.1007 / \mathrm{s} 12126-010-9095-7$

Heinrich, L. M. \& Gullone, E. (2006). The clinical significance of loneliness: A literature review. Clinical Psychology Review, 26, 695-718. https://doi.org/10.1016/j.cpr.2006.04.002

HM Government (2018). A connected society: A strategy for tackling loneliness. Department for Digital, Culture, Media and Sport. https://www.gov.uk/government/publications/aconnected-society-a-strategy-for-tackling-loneliness

Independent Age/Mori (2005). Attitudes to growing older. https://www.ipsosmori.com/researchpublications/researcharchive/545/Attitudes-To-Growing-Older.aspx.

Jisc [Joint Information Systems Committee] (no date). Zetoc informing research. http://zetoc.jisc.ac.uk/about.html

Jo Cox Loneliness (2017). Combatting loneliness one conversation at a time. The Jo Cox Foundation. https://www.ageuk.org.uk/globalassets/age-uk/documents/reports-and-publications/reportsand-briefings/active-communities/rb_dec17_jocox_commission_finalreport.pdf

Jopling, K. (2015). Promising approaches: Reducing loneliness and isolation in later life. Age UK/ Campaign to end loneliness. https://www.campaigntoendloneliness.org/wpcontent/uploads/Promising-approaches-to-reducing-loneliness-and-isolation-in-later-life.pdf

Katz, J., Holland, C., Peace, S. \& Taylor, E. (2011). A better life: What older people with high support needs value. Joseph Rowntree Foundation. 
https://www.jrf.org.uk/sites/default/files/jrf/migrated/files/older-people-and-high-supportneeds-full.pdf

Keating, N., Otfinowski, P., Wenger, C., Fast, J. \& Derksen, L. (2003). Understanding the caring capacity of informal networks of frail seniors: a case for care networks. Ageing \& Society, 23, 115-127. https://doi.org/10.1017/S0144686X02008954

Kempton, J. \& Tomlin, S. (2014). Ageing alone: Loneliness and the 'oldest old'. Centre Forum/Age UK. https://cminteractive.net/ci/centreforum/tomfrostick/ageingalone.pdf

Kharicha, K., lliffe, S., Harari, D., Swift, C., Gillmann, G. \& Stuck, A. E. (2007). Health risk appraisal in older people 1: Are older people living alone an 'at-risk'group? British Journal of General Practice, 57, 271-276. https://bjgp.org/content/bjgp/57/537/271.full.pdf

Kharicha, K., liffe, S., Manthorpe, J., Chew-Graham, C. A., Cattan, M., Goodman, C., Kirby-Barr, M., Whitehouse, J. H. \& Walters, K. (2017). What do older people experiencing loneliness think about primary care or community based interventions to reduce loneliness? A qualitative study in England. Health \& Social Care in the Community. doi: 10.1111/hsc.12438

Killeen, C. (1998). Loneliness: An epidemic in modern society. Journal of Advanced Nursing, 28, 762770. https://doi.org/10.1046/j.1365-2648.1998.00703.x

Kirkevold, M., Moyle, W., Wilkinson, C., Meyer, J. \& Hauge, S. (2013). Facing the challenge of adapting to a life 'alone' in old age: The influence of losses. Journal of Advanced Nursing, 69, 394-403. https://doi.org/10.1111/j.1365-2648.2012.06018.x

Kitzmüller, G., Clancy, A., Vaismoradi, M., Wegener, C. \& Bondas, T. (2018). “Trapped in an empty waiting room", the existential human core of loneliness in old age: A metasynthesis. Qualitative Health Research, 28, 213-230.

https://doi.org/10.1177/1049732317735079 
Kneale, D. (2012). Is social exclusion still important for older people? International Longevity Centre. https://ilcuk.org.uk/wp-content/uploads/2018/11/Social-exclusion-Report.pdf

Koelet, S. \& de Valk, H. A. (2016). Social networks and feelings of social loneliness after migration: The case of European migrants with a native partner in Belgium. Ethnicities, 16, 610-630. https://doi.org/10.1177/1468796816638398

La Grow, S., Neville, S., Alpass, F. \& Rodgers, V. (2012). Loneliness and self-reported health among older persons in New Zealand. Australasian Journal on Ageing, 31, 121-

123. https://doi.org/10.1111/j.1741-6612.2011.00568.x

Larson, R. W. (1999). The uses of loneliness in adolescence. In Rotenberg, K. J. \& Hymel, S. (eds.). Loneliness in childhood and adolescence. Cambridge University Press, 244-262.

Lawlor, B., Golden, J., Paul, G., Walsh, C., Conroy, R., Holfeld, E. \& Tobin, M. (2014). Only the lonely. Age Friendly Ireland. https://www.researchgate.net/publication/269392000_Only_the_Lonely_a_randomized_cont rolled_trial_of_a_volunteer_visiting_programme_for_older_people_experiencing_loneliness

Lee, S. (2013). A study on exploring people's affinity for solitude (Doctoral dissertation). College Station: Texas A\&M University. https://core.ac.uk/download/pdf/17050127.pdf

Liljas, A. E. M., Walters, K., Jovicic, A., Iliffe, S., Manthorpe, J., Goodman, C. \& Kharicha, K. (2017). Strategies to improve engagement of 'hard to reach' older people in research on health promotion: A systematic review. BMC Public Health, 17, 349. doi: 10.1186/s12889-017-42418.

Lloyd, J. (2008). The state of intergenerational relations today. International Longevity Centre UK. https://ilcuk.org.uk/wp-content/uploads/2018/10/StateofItergenerationalRelations.pdf 
Luhmann, M., \& Hawkley, L. C. (2016). Age differences in loneliness from late adolescence to oldest old age. Developmental Psychology, 52, 943-959. https://doi.org/10.1037/dev0000117

Martín-María, N., Caballero, F. F., Miret, M., Tyrovolas, S., Haro, J. M., Ayuso-Mateos, J. L. \& Chatterji, S. (2020). Differential impact of transient and chronic loneliness on health status. A longitudinal study. Psychology \& Health, 35, 177-195.

https://doi.org/10.1080/08870446.2019.1632312

Martire, L. M. \& Franks, M. M. (2014). The role of social networks in adult health: Introduction to the special issue. Health Psychology, 33, 501-504. https://doi.org/10.1037/hea0000103

Masi, C. M., Chen, H. Y., Hawkley, L. C. \& Cacioppo, J. T. (2011). A meta-analysis of interventions to reduce loneliness. Personality \& Social Psychology Review, 15, 219-266. https://doi.org/10.1177/1088868310377394

McHugh, J. E., Kenny, R. A., Lawlor, B. A., Steptoe, A. \& Kee, F. (2016). The discrepancy between social isolation and loneliness as a clinically meaningful metric: Findings from the Irish and English longitudinal studies of ageing (TILDA and ELSA). International Journal of Geriatric Psychiatry, 32, 664-674. https://doi.org/10.1002/gps.4509

McLeod, E., Bywaters, P., Tanner, D. \& Hirsch, M. (2006). For the sake of their health: Older service users' requirements for social care to facilitate access to social networks following hospital discharge. British Journal of Social Work, 38, 73-90. https://doi.org/10.1093/bjsw/bcl341

Metzner, J. L. \& Fellner, J. (2010). Solitary confinement and mental illness in US prisons: A challenge for medial ethics. Journal of the American Academy of Psychiatry \& the Law, 38, 104-108. http://jaapl.org/content/jaapl/38/1/104.full.pdf

Moriarty, J., \& Manthorpe, J. (2017). The diversity of befriending by, and of, older people. Working with Older People, 21, 63-71. https://doi.org/10.1108/WWOP-07-2016-0017 
Mortimer, J. (2016). No one should have no one: Working to end loneliness amongst older people. Age UK. https://www.ageuk.org.uk/Documents/EN-GB/No-one_Should_Have_Noone_Working_to_end_loneliness.pdf?dtrk=true

Ngan, R. (2011). Social care and older people. In Stuart Hamilton, I. (ed.). An introduction to social gerontology. Cambridge University Press, 126-158.

NHS (2018). Loneliness in older people. https://www.nhs.uk/conditions/stress-anxietydepression/loneliness-in-older-people/

Ni Lieme, A. \& Connolly, S. (2015). Acitve ageing: Social participation and ageing in later life. In Walsh, K., Carney, G. M. \& Ni Lieme, A. (eds.). Ageing through austerity: Critical perspectives from Ireland. Policy Press, 47-62.

Nyqvist, F., Cattan, M., Andersson, L., Forsman, A. K. \& Gustafson, Y. (2013). Social capital and loneliness among the very old living at home and in institutional settings: A comparative study. Journal of Aging \& Health, 25, 1013-1035.

https://doi.org/10.1177/0898264313497508

O'Luanaigh, C., \& Lawlor, B. A. (2008). Loneliness and the health of older people. International Journal of Geriatric Psychiatry, 23, 1213-1221. https://doi.org/10.1002/gps.2054

Pahl, R. \& Prevalin, D. J. (2005). Between family and friends: A longitudinal study of friendship choice. British Journal of Sociology, 56, 432-450. https://doi.org/10.1111/j.14684446.2005.00076.x

Palgi, Y., Shrira, A., Ben-Ezra, M., Shiovitz-Ezra, S. \& Ayalon, L. (2002). Self- and other oriented potential lifetime traumatic events as predictors of loneliness in the second half of life. Aging \& Mental Health, 16, 423-430. https://doi.org/10.1080/13607863.2011.638903 
Qualter, P., Vanhalst, J., Harris, R., Van Roekel, E., Lodder, G., Bangee, M., Maes, M. \& Verhagen, M. (2015). Loneliness across the life span. Perspectives on Psychological Science, 10, 250-264. https://doi.org/10.1177/1745691615568999

Ray, M., Milne, A., Beech, C., Phillips, J. E., Richards, S., Sullivan, M. P., Tanner, D. \& Lloyd, L. (2014). Gerontological social work: Reflections on its role, purpose and value. British Journal of Social Work, 45, 1296-1312. https://doi.org/10.1093/bjsw/bct195

Routasalo, P. E., Savikko, N., Tilvis, R. S., Strandberg, T. E. \& Pitkala, K. H. (2006). Social contacts and their relationships to loneliness among aged people: A population-based study. Gerontology, 52, 181-187. https://doi.org/10.1159/000091828

Rozanova, J., Keating, N. \& Eales, J. (2012). Unequal social engagement for older adults: Constraints on choice. Canadian Journal on Aging, 31, 25-

36. https://doi.org/10.1017/S0714980811000675

Saito, T., Kai, I. \& Takizawa, A. (2012). Effects of a program to prevent social isolation on loneliness, depression and subjective well-being of older adults: A randomized trial among older migrants in Japan. Archives of Gerontology \& Geriatrics, 55, 539-547.

https://doi.org/10.1016/j.archger.2012.04.002

Savva, G., Hanly, M., McDaid, O., Richardson, K., Kenny, R. A. \& Kee, F. (2011). Multimorbidity in the older population. Centre for ageing research and development in Ireland. https://www.lenus.ie/bitstream/handle/10147/202430/Multimorbidity\%20\%28Briefing\%20Pa per\%29\%20Web\%20\%282\%29\%281\%29.pdf?sequence=1\&isAllowed=y

Scharf, T. (2015). Between inclusion and exclusion in later life. In Walsh, K., Carney, G. M. \& Ni Lieme, A. (eds.). Ageing through austerity: Critical perspectives from Ireland. Policy Press, 113130. 
Shiovitz-Ezra, S. \& Ayalon, L. (2012). Use of direct versus indirect approaches to measure loneliness in later life. Research on Aging, 34, 572-591. https://doi.org/10.1177/0164027511423258

Shiovitz-Ezra, S. \& Leitsch, S. A. (2010). The role of social relationships in predicting loneliness: The National Social Life, Health, and Aging Project. Social Work Research, 34, 157-167. https://doi.org/10.1093/swr/34.3.157

Smith, J. M. (2012). Toward a better understanding of loneliness in community-dwelling older adults. The Journal of Psychology, 146, 293-311. https://doi.org/10.1080/00223980.2011.602132

Smith, K. J., \& Victor, C. R. (2019). Typologies of loneliness, living alone and social isolation, and their associations with physical and mental health. Ageing \& Society, 39, 17091730. https://doi.org/10.1017/S0144686X18000132

Steed, L., Boldy, D., Grenade, L. \& Iredell, H. (2007). The demographics of loneliness among older people in Perth, Western Australia. Australasian Journal on Ageing, 26, 81-86. https://doi.org/10.1111/j.1365-2524.2010.00923.x

Stewart, M., Craig, D., MacPherson, K., \& Alexander, S. (2001). Promoting positive affect and diminishing loneliness of widowed seniors through a support intervention. Public Health Nursing, 18, 54-63. https://doi.org/10.1046/j.1525-1446.2001.00054.x

Stokes, J. E. (2016). Marital quality and loneliness in later life: A dyadic analysis of older married couples in Ireland. Journal of Social and Personal Relationships, 34, 114-135. https://doi.org/10.1177/0265407515626309 
Stone, J., Evandrou, M., Pourghasem, M. \& Hughes, I. (2009). Internet use as a predictor of sense of community in older people. Cyberpsychology \& Behavior, 12, 235-239. https://doi.org/10.1089/cpb.2008.0150

Thompson, J. (2016). Transforming health and social care in Northern Ireland: Services and governance. Northern Ireland Assembly Briefing Paper.

van den Berg, P., Kemperman, A., de Kleijn, B. \& Borgers, A. (2016). Ageing and loneliness: The role of mobility and the built environment. Travel Behaviour \& Society, 5, 48-55. http://www.niassembly.gov.uk/globalassets/documents/raise/publications/20162021/2016/health/4016.pdf

van Roekel, E., Verhagen, M., Engels, R. C., Scholte, R. H., Cacioppo, S., \& Cacioppo, J. T. (2018). Trait and state levels of loneliness in early and late adolescents: Examining the differential reactivity hypothesis. Journal of Clinical Child \& Adolescent Psychology, 47, 888-899. https://doi.org/10.1080/15374416.2016.1146993

van Winkel, M., Wichers, M., Collip, D., Jacobs, N., Derom, C., Thiery, E., Myen-Germeys, I. \& Peeters, F. (2017). Unraveling the role of loneliness in depression: The relationship between daily life experience and behavior. Psychiatry, 80, 104-117. https://doi.org/10.1080/00332747.2016.1256143

Victor, C. R. \& Bowling, A. (2012). A longitudinal analysis of loneliness among older people in Great Britain. The Journal of Psychology, Interdisciplinary \& Applied, 146, 313-331. https://doi.org/10.1080/00223980.2011.609572 
Victor, C. R., Grenade, L. \& Boldy, D. (2005). Measuring loneliness in later life: A comparison of differing measures. Reviews in Clinical Gerontology, 15, 63-

70. https://doi.org/10.1017/S0959259805001723

Victor, C. R., Scambler, S. J. \& Bond, J. (2009). The social world of older people: Understanding Ioneliness and social isolation in later life. Open University Press.

Victor, C. R. \& Yang, K. (2012). The prevalence of loneliness among adults: A case study of the United Kingdom. The Journal of Psychology: Interdisciplinary \& Applied, 146, 85-104. https://doi.org/10.1080/00223980.2011.613875

Walker, J., Orpin, P., Baynes, H., Stratford, E., Boyer, K., Mahjouri, N., Patterson, C., Robinson, A. \& Carty, J. (2013). Insights and principles for supporting social engagement in rural older people. Ageing \& Society, 33, 938-963. https://doi.org/10.1017/S0144686X12000402

Walsh, K., O'Shea, E. \& Scharf, T. (2012). Social exclusion and ageing in diverse rural communities. Irish Centre for Social Gerontology/Healthy Ageing in Rural Communities. http://citeseerx.ist.psu.edu/viewdoc/download?doi=10.1.1.426.9536\&rep=rep1\&type=pdf

Warburton, J., Scharf, T. \& Walsh, K. (2016). Flying under the radar? Risks of social exclusion for older people in rural communities in Australia, Ireland and Northern Ireland. Sociologica Ruralis. doi: 10.1111/soru.12129.

Warner, D. F. \& Adams, S. A. (2016). Physical disability and increased loneliness among married older adults: The role of changing social relations. Society and Mental Health, 6, 106-128. https://doi.org/10.1177/2156869315616257

Warner, D. F. \& Kelley-Moore, J. (2012). The social context of disablement among older adults: Does marital quality matter for loneliness? Journal of Health and Social Behavior, 53, 50-66. https://doi.org/10.1177/0022146512439540 
Weiss, R. S. (1973). Loneliness: The experience of emotional and social loneliness. Massachusetts Institute of Technology.

Wenger, G. C. (1997). Social networks and the prediction of elderly people at risk. Aging \& Mental Health, 1, 311-320. https://doi.org/10.1080/13607869757001

Wood, L. A. (1986). Loneliness. In Harre, R. (ed.). The social construction of emotions. Oxford: Basil Blackwell, 184-208.

Woodhouse, S. S., Dykas, M. J., \& Cassidy, J. (2012). Loneliness and peer relations in adolescence. Social Development, 21, 273-293. https://doi.org/10.1111/j.1467-9507.2011.00611.x

WRVS (2012). Loneliness amongst older people and the impact of family connections. https://www.royalvoluntaryservice.org.uk/Uploads/Documents/How_we_help/lonelinessamongst-older-people-and-the-impact-of-family-connections.pdf

Yi, Y., Li, L. M. W., Xiao, Y., Ma, J., Fan, L., \& Dai, Z. (2018). Brain activity mediates the relation between emotional but not instrumental support and trait loneliness. Social Cognitive and Affective Neuroscience, 13, 995-1002. https://doi.org/10.1093/scan/nsy067 